\title{
Assessment of the rate of human aging by clinical biochemical tests
}

\author{
Anatoly V. Pisaruk, Ivanna A. Antoniuk-Shcheglova, Svitlana S. Naskalova, Olena V. Bondarenko, \\ Valerii B. Shatylo, Ludmila V. Mekhova
}

State Institution “D. F. Chebotarev Institute of Gerontology NAMS of Ukraine”, Kyiv, Ukraine

Correspondence: nkoshel11@gmail.com

Received: 12.04.2021; Accepted: 26.04.2021; Published: 05.05.2021

\begin{abstract}
The aim of the study was the development of the accessible method for assessing the rate of human aging by laboratory biochemical parameters. There were examined 408 practically healthy people in the age from 20 to 80 years. There were determined 6 anthropometric and 14 laboratory biochemical parameters, characterizing carbohydrate and fat metabolism, liver and kidney functions. The use of stepwise multiple regression made it possible to select the most informative indicators and obtain an equation linking the age of the examined people with a number of anthropometric and metabolic indicators. The average absolute error in calculating age was 4.2 years. The method for assessing the rate of aging, developed by us, is highly accurate and can be used to assess the risk of developing of the agedependent pathology.
\end{abstract}

Key worlds: biological age; metabolic biomarkers of aging

The determination of the biological age (BA) is a technology (tool) for the assessing of the degree of development of age - dependent changes, the rate of aging and the diagnosis of accelerated aging [1-4]. BA can either coincide with chronological age (CA), and in that case the aging process is assessed as normal, physiological, or significantly exceed CA [5]. In the latter case, the aging is assessed as accelerated. It is known, that in the process of aging such changes in organs and systems occur that make a contribution to the development of a number of diseases, primarily cardiovascular diseases. Rapidly aging people have a high risk of developing of the age-associated pathology [6-9]. They need a lifestyle and nutrition correction, refusal of the bad habits and periodic medical supervision at the health center. This will slow down the rate of aging and reduce the risk of developing age- dependent pathology.

The calculation of BA in most of the works is based on the measurement of quantitative indicators that are called biological markers of aging. These indicators should correlate with age, be available for measurement in a clinical setting, and be dependent not much on the actual pathological conditions. A variety of indicators can act as biological markers: anatomical, functional, biochemical, immunological, genetic, and epigenetic [9-11].

The generally accepted mathematical method for assessing BA is the calculation of the equation of the multiple regression linking CA and a number of quantitative indicators [12-13]. For the determination of the coefficients of this equation, the survey data of a large number of practically healthy people of different ages are used. To determine the BA of the subject, a number of studies are carried out for him and his age is calculated in the accordance with the obtained formula. If the estimated age significantly exceeds CA, a conclusion is made about the accelerated aging of this person. 


\section{Materials and methods}

The study included 408 practically healthy people aged from 20 to 80 years, who were examined at the Department of Clinical Physiology and Pathology of Internal Organs of the State Institution «D.F. Chebotarev Institute of Gerontology of the National Academy of Medical Sciences of Ukraine». People with the pathologies of the cardiovascular, respiratory, endocrine and central nervous systems, chronic liver and kidney diseases, and pathologies of the hematopoietic system were excluded from the analysis.

There were determined 6 anthropometric and 14 laboratory biochemical parameters characterizing carbohydrate and fat metabolism, liver and kidney functions.

Anthropometric measurements included determination of body weight (in $\mathrm{kg}$ ), height (in $\mathrm{cm}$ ), body mass index (BMI, in $\mathrm{kg} / \mathrm{m} 2)$, waist circumference (WC, in $\mathrm{cm})$, hip circumference $(\mathrm{HC}$, in $\mathrm{cm}$ ), correlation WC/HC.

Body weight was measured with the help of stationary balance with an accuracy of $0.1 \mathrm{~kg}$ among the persons wearing light clothes without shoes. Height was measured with an accuracy of $0.5 \mathrm{~cm}$ among the persons without shoes. Body mass index was calculated as the ratio of body weight (in kilograms) to height (in meters squared).

Waist circumference was measured with a measuring tape among the persons in a standing position without clothes, at the waist after exhalation - in the middle between the back part of the lateral costal arch and the crest of the pelvic bone (WHO standard). The hips circumference was measured at the level of the large trochanter of the femur. Also the index of the ratio of the circumference of the waist to the circumference of the hips $(\mathrm{CW} / \mathrm{CH})$ was calculated. The value of $\mathrm{CW} / \mathrm{CH}$ for men>1.0 and women> 0.85 indicates an abdominal type of obesity.

Biochemical parameters of carbohydrate metabolism included the determination of blood plasma glucose level by the glucose oxidase method. For the identifying of the latent disorders of carbohydrate metabolism, a standard oral glucose tolerance test was performed in accordance with the WHO methodology (WHO Consultation, 1999) and the American Association of studying of Diabetes (American Diabetes Association / ADA, 1997) [15].

For the assessment of lipid metabolism, the levels of total cholesterol TC, high density lipoprotein cholesterol (HDL cholesterol), low density lipoprotein cholesterol (LDL cholesterol), very low density lipoprotein cholesterol (VLDL cholesterol) and triglycerides (TG) in serum were determined. The levels of TC and TG were investigated by the enzymatic-colorimetric method using BIO SYSTEMS reagents, HDL cholesterol - by the method of precipitation with phosphoric-tungstic acid. The calculation of the indicators of LDL cholesterol and VLDL cholesterol was carried out in accordance with the accepted mathematical formulas.

All biochemical parameters, including indicators of liver function (alanine aminotransferase (ALT), aspartate aminotransferase (AST), alkaline phosphatase) and kidney (creatinine, urea) were determined on an automatic biochemical analyzer "BM Autolab PM 4000/3" manufactured by "Boehringer Mannheim" in the laboratory of the clinic of the Institute of Gerontology.

Statistical processing of the obtained data was carried out with the help of Excel 2007 and Statistica 7 programs. Standard statistical procedures, including variation and regression analyses, were used.

\section{Results and discussion}

The preliminary stage in calculating of the formula of biological age was the analysis of the dependence of the studied parameters on the age of the examined people. The table shows the correlation of the coefficients of the studied indicators with the age (R). 


\section{Correlations with Age}

\begin{tabular}{|l|c|}
\hline Biological markers & $\mathbf{R}$ \\
\hline Anthropometric indicators & $\mathbf{0 . 1 2}$ \\
\hline Weight, & $\mathbf{0 . 3 0}$ \\
\hline Growth & $\mathbf{0 . 3 3}$ \\
\hline BMI, $\mathrm{kg} / \mathrm{m}^{2}$ & $\mathbf{0 . 3 4}$ \\
\hline Waist, sm & $\mathbf{0 . 2 4}$ \\
\hline Hips, sm & $\mathbf{0 . 4 0}$ \\
\hline Waist/Hips & \\
\hline Laboratory indicators & $\mathbf{0 . 3 0}$ \\
\hline Blood glucose, mmol/l & $\mathbf{0 . 3 6}$ \\
\hline Glucose 2 hours $(\mathrm{GTT}), \mathrm{mmol} / \mathrm{l}$ & $\mathbf{0 . 1 8}$ \\
\hline Cholesterol, blood chemistry, $\mathrm{mmol} / \mathrm{l}$ & $\mathbf{0 . 2 4}$ \\
\hline Triglycerides, $\mathrm{mmol} / \mathrm{l}$ & -0.06 \\
\hline HDL cholesterol, $\mathrm{mmol} / \mathrm{l}$ & $\mathbf{0 . 1 1}$ \\
\hline LDL cholesterol, $\mathrm{mmol} / \mathrm{l}$ & $\mathbf{0 . 2 5}$ \\
\hline VLDL cholesterol, $\mathrm{mmol} / \mathrm{l}$ & $\mathbf{0 . 1 4}$ \\
\hline Atherogenic index & $\mathbf{0 . 2 4}$ \\
\hline Urea, mmol/l & $\mathbf{0 . 1 1}$ \\
\hline Creatinine, mmol/l & $\mathbf{0 . 2 0}$ \\
\hline Uric acid, mmol/l & $\mathbf{0 . 1 1}$ \\
\hline ALT, $\mathrm{u} / \mathrm{l}$ & -0.06 \\
\hline AST, u/l & $\mathbf{0 . 4 1}$ \\
\hline Alkaline phosphatase, $\mathrm{u} / \mathrm{l}$ & \\
\hline
\end{tabular}

Note: Marked correlations are significant at $p<0.05$

The use of stepwise multiple regression made it possible to select the most informative indicators and obtain an equation linking the age of the examined people with a number of anthropometric and metabolic indicators $(r=0.62 ; p<0.0001)$.

$$
\mathrm{Y}=0.55 \mathrm{X} 1+39.2 \mathrm{X} 2+3.37 \mathrm{X} 3+4.44 \mathrm{X} 4+1.40 \mathrm{X} 5-0.27 \mathrm{X} 6+0.13 \mathrm{X} 7-30.0
$$

$\mathrm{Y}$ - Predicted age, years

$\mathrm{X} 1$ - BMI, $\mathrm{kg} / \mathrm{m}^{2}$;

X2 - Waist/Hips;

X3 - Glucose 2 hours (GTT), mmol/l;

X4 - VLDL cholesterol, $\mathrm{mmol} / \mathrm{l}$;

$\mathrm{X} 5$ - Urea, $\mathrm{mmol} / \mathrm{l}$

$\mathrm{X} 6-\mathrm{ALT}, \mathrm{u} / \mathrm{l}$

X7 - Alkaline phosphatase, $\mathrm{u} / \mathrm{l}$.

The systematic error in calculating of the age, associated with the peculiarities of constructing of the multiple regression equation is calculated using the regression equation: prognosticated age chronological age [16]. For our data, this error is calculated by the formula:

$$
\text { Age calculation error }=38.88-0.646 \mathrm{CA} \text {. }
$$

In turn, $\mathrm{BA}$ is calculated as the difference between the predicted age $(\mathrm{Y})$ and the error in its calculation. 
The figure shows a graph of the correlation between BA after error correction and CA. It can be seen that the dispersion of points around the regression line is small and the multiple correlation coefficient is high $(r=0.902 ; p<0.00001)$.

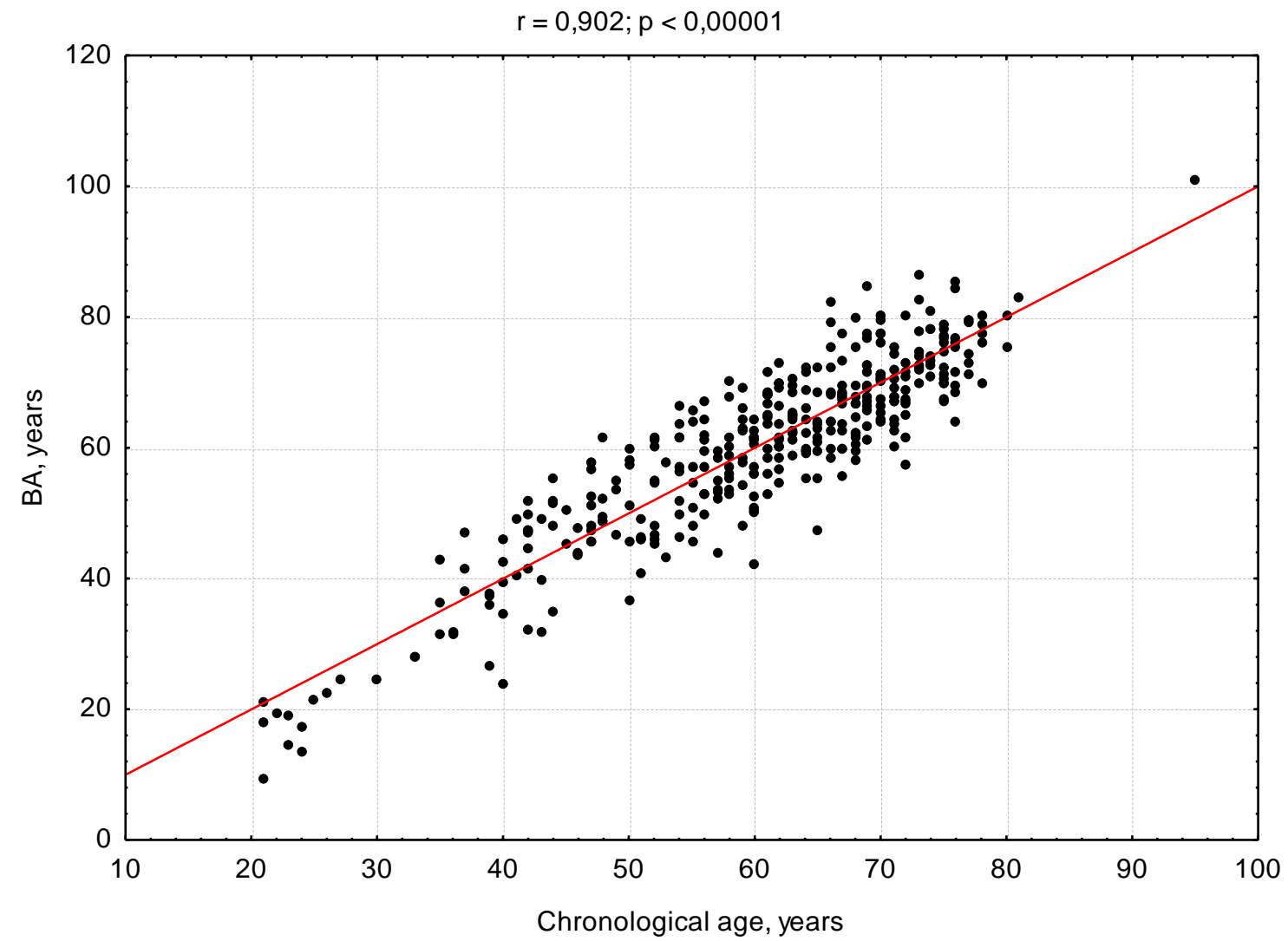

Figure. Correlation between biological and chronological age of people.

The average absolute value of the error of BA calculation, in this case, is 4.2 years. If we consider, as it is used to believe, people with accelerated aging, whose BA exceeds CA by 10 years, then the proportion of such people among the surveyed people is $9.1 \%$.

Thus, the method for assessing the rate of aging developed by us, has a high accuracy and can be used to assess the risk of developing age-dependent pathology, primarily, cardiovascular and diabetes mellitus of the second type. Simple anthropometric measurements and laboratory tests used in clinical laboratories are sufficient for the use of this method. The implementation of the proposed method will allow not only to identify people with the risk of developing pathology, but also to assess the effectiveness of treatment, prophylactic and rehabilitation measures.

Author Contributions: All authors participated equally in writing this commentary.

Conflicts of Interest: The authors declare no conflict of interest.

Information about Authors:

Anatoly V. Pisaruk - DSc (Medicine), Head of the Laboratory for Mathematical Modeling of Aging Processes; https://orcid.org/0000-0001- 5522-0172

Ivanna A. Antoniuk-Shcheglova - DSc (Medicine), Leading Researcher of the Department of Clinical Physiology and Pathology of Internal Organs; https://orcid.org/0000-0002-6122-8266

Svitlana S. Naskalova - PhD (Medicine), Senior Researcher of the Department of Clinical Physiology and Pathology of Internal Organs; https://orcid.org/0000-0001-9518-2633

Olena V. Bondarenko- PhD (Medicine), Senior Researcher of the Department of Clinical Physiology and Pathology of Internal Organs; https://orcid.org/0000-0002-8270-5316

Valerii B. Shatylo - DSc (Medicine), Prof., Leading Researcher of the Department of Clinical Physiology and Pathology of Internal Organs, Deputy Director for Research; https://orcid.org/0000-0001-6420-000X

Ludmila V.Mekhova - PhD (Medicine), Senior Researcher of the Laboratory for Mathematical Modeling of Aging Processes; https://orcid.org/0000-0002-8445-1719 


\section{References}

1. Salthouse, T. A. Aging and measures of processing speed. Biol. Psychol. 2000, 1-3, pp. 35-54. doi: 10.1016/s0301-0511(00)00052-1

2. Cevenini, E.; Invidia, L.; Lescai, F.; Salvioli, S.; Tieri, P. et al. Human models of aging and longevity. Expert Opinion on Biological Therapy 2015, 8, pp. 1393-1405. doi: 10.1517/14712598.8.9.1393

3. Belsky,a D. W.; Caspic, A.; Houtsc, R.; Cohen, H. J.; Corcoran, D. L. et al. Quantification of biological aging in young adults. PNAS 2015, p. 27. doi: 10.1073/pnas.1506264112

4. Sprott, R. L. Biomarkers of aging and disease: introduction and definitions. Exp. Gerontol. 2010,.45, pp. 2-4. doi: 10.1016/j.exger.2009.07.008

5. Korkushko, O. V.; Khavynson, V. Kh.; Shatylo, V. B.; Antoniuk-Schehlova, Y. A. Peptydnyj heroprotektor yz epyfyza zamedliaet uskorennoe starenne pozhylykh liudej: rezul'taty 15-letneho nabliudenyia. Biulleten eksperym. byol.y medytsyny. 2011, 151, pp. 343-348.

6. Mitnitski, A. B.; Graham, J. E.; Mogilner, A. J.; Rockwood, K. Frailty, fitness and late-life mortality in relation to chronological and biological age. BMC Geriatr. 2002, 2, p. 1. doi: 10.1186/1471-2318-2-1

7. Morgan, E. L. Modeling the Rate of Senescence: Can Estimated Biological Age Predict Mortality More Accurately Than Chronological Age? Journals of Gerontology: Biological Sciences Cite journal as: J Gerontol A Biol Sci Med Sci. 2013, 68, pp. 667-674. doi:10.1093/gerona/gls233

8. Kasagi, F.; Yamada, M.; Sasaki, H.; Fujita, Sh. Biologic Score and Mortality Based on a 30-Year Mortality Follow-Up: Radiation Effects Research Foundation Adult Health Study. J. Gerontol. Biol. Sci. 2009, 64A, pp. 865-870. doi:10.1093/gerona/glp025

9. Burkle, A.; Moreno-Villanueva, M.; Bernhard, J.; Blasco, M.; Zondag, G. et al. MARK-AGE biomarkers of ageing. Mech. Ageing Dev. 2015, 151, pp. 2-12. doi: 10.1016/j.mad.2015.03.006

10. Moreno-Villanueva, M.; Capri, M.; Breusing, N.; Siepilmeyer, A.; Sevini, F. et al. MARK-AGE standard operating procedures (SOPs): A successful effort. Mech. Ageing Dev. 2015, 151, pp. 18-25. doi: 10.1016/ j. mad. 2015.03.007

11. Xia, X.; Chen, W.; McDermott, J.; Han, J-D. J. Molecular and phenotypic biomarkers of aging: Version 1. F1000 Res. 2017, 6, p. 860. doi: 10.12688/ f1000research. 10692.1

12. Krøll, J.; Saxtrup, O. On the use of regression analysis for the estimation of human biological age. Biogerontology. 2000, 1, pp. 363-368. doi: 10.1023/a:1026594602252

13. Caballero, F. F.; Soulis, G.; Engchuan, W.; Sanchez-Niubo, A.; Arndt, H. et al. Advanced analytical methodologies for measuring healthy ageing and its determinants, using factor analysis and machine learning techniques: the ATHLOS project. Sci Rep. 2017, 7, p. 43955. doi: 10.1038/srep43955

14. Korkushko, O. V.; Pisaruk, A. V.; Chyzhova, V. P. Estimation of human metabolic age using regression and neural network analysis. Zaporozhye medical journal. 2021, 23, pp. 60-64. doi: 10.14739/2310-1210.2021.1.224883

15. Ryden, L.; Standl, E.; Bartnik, M. et al. The Task Force on Diabetes and Cardiovascular Diseases of the European Society of Cardiology (ESC) and of the European Association for the Study of Diabetes (EASD). Eur. Heart J. 2007, 28, pp. 88-136.

16. Pisaruk, A. V. A simple method for correction of the systematic error in calculating biological age by the multiple regression equation. Aging and longevity 2021, 2, pp.11-16. doi: 10.47855/jal9020-2021-1-2 